\title{
Poison pills no Brasil: um estudo exploratório
}

\section{Poison pills in Brazil: an exploratory study}

\author{
Jorge Vieira \\ Professor Doutor do Programa de Mestrado em Contabilidade da Faculdade de Administração e Finanças da Universidade do Estado do Rio de \\ Janeiro•E-mail: jorgevcosta@terra.com.br
}

\section{Eliseu Martins}

Professor Emérito da Faculdade de Economia, Administração e Contabilidade da Universidade de São Paulo • E-mail: emartins@usp.br

Luiz Paulo Lopes Fávero

Professor Doutor do Departamento de Contabilidade e Atuária da Faculdade de Economia, Administração e Contabilidade da Universidade de São Paulo• E-mail: Ipfavero@usp.br

Recebido em 16.03.2007 • Aceito em 07.08:2007 • $2^{a}$ versão aceita em 16.08.2007

\section{RESUMO}

O objetivo precípuo deste trabalho foi fazer uma incursão sobre as poison pills. Quais são os aspectos conceituais, assim como as disposições legais e regulamentares aplicáveis às poison pills. Um levantamento das companhias abertas que se valem do referido instrumento defensivo, com corte até junho de 2006, foi procedido, de modo a saber que peculiaridades podem ser observadas em nosso ambiente. Ainda quanto ao objetivo do trabalho, foram apreciadas teorias que procuram explicar o comportamento de administradores de companhias com poison pills em termos de alinhamento de interesses pessoais com os da firma. Com este estudo exploratório, espera-se que uma nova área de pesquisa empírica possa ser desenvolvida no Brasil. Teorias aqui apresentadas podem e devem ser objeto de investigações futuras, de modo a se contribuir com a literatura sobre o tema no Brasil. É de todo prudente considerar nos trabalhos empíricos aspectos idiossincráticos do mercado de capitais brasileiro e a própria prematuridade dessas companhias, antes de qualquer conclusão friamente calcada nos números.

Palavras-chave: Poison pills. Controle pulverizado. Tomada de controle hostil. Oferta pública.

\section{ABSTRACT}

This paper aimed to study poison pills, investigate the conceptual aspects, as well as legal dispositions and other rules applicable. A research of publicly-held firms that use this anti-takeover instrument was done, sampled till June 2006, in order to discover peculiarities in the Brazilian environment. Moreover, as an objective of this paper, some theories that can explain the behavior of managers from poison pill firms were presented, focused on the classical agency problem: managers' interest against firms' interest. This exploratory study should support the development of a new empirical research area in Brazil. Theories here presented can and should be investigated in future research, in order to improve Brazilian literature focused on this matter. Nevertheless, it would be prudent to consider the idiosyncratic aspects of the Brazilian Stock Market and precocity of these poison pill firms in empirical studies, before coming to any conclusion about the figures and measures obtained.

Keywords: Poison pills. Publicly-held firms. Hostile take over. Tender offer. 


\section{INTRODUÇÃO}

\subsection{Contextualização do problema}

Em ambientes de mercado de capitais bem desenvolvidos, em que as companhias abertas são eminentemente públicas, com ações com poder de voto distribuídas de modo pulverizado, sem um controlador identificado, não é raro testemunhar, por vezes, contendas privadas derivadas de operações de oferta pública voltadas à aquisição de controle acionário. As denominadas aquisições hostis.

Observam-se, em alguns casos, verdadeiras batalhas pela conquista do controle acionário de uma dada companhia (take over ${ }^{1}$. De um lado, os atuais administradores da companhia-alvo, valendo-se de instrumentos de defesa disponíveis e apropriados a uma situação específica, variando do mais simples, como o processo de persuasão dos acionistas pela não adesão à oferta pública de aquisição - $\mathrm{OPA}^{2}$, aos mais complexos, como as estratégias de poison pill, shark repellent, entre outras. De outro, os proponentes compradores, na sua árdua tarefa de convencerem a vasta gama de acionistas da companhia-alvo a aceitarem sua oferta de compra, que pode contemplar pagamentos em dinheiro, em ações da companhia compradora, ou na combinação de ambos.

No Brasil, as bem sucedidas ofertas públicas de venda de ações dos últimos anos - distribuições registradas na CVM para os mercados primário e secundário - fizeram surgir um fenômeno até então inimaginável na cultura empresarial brasileira: companhias abertas eminentemente públicas. Tal fato é uma evidência do quão evoluído está o mercado de capitais brasileiro, caminhando para níveis de excelência de economias mais pujantes.
É de se salientar que ditas companhias com controle pulverizado e algumas outras com controle concentrado, porém com boa dispersão acionária, já dispõem de disposições estatutárias que evitam uma eventual aquisição hostil (as chamadas poison pills). Esse tema, dado o seu caráter emergente, será objeto deste estudo.

\subsection{Objetivos da Pesquisa}

O objetivo precípuo deste trabalho é o de fazer uma incursão sobre o tema. Quais são os aspectos conceituais, assim como as disposições legais e regulamentares aplicáveis às poison pills. Um levantamento das companhias abertas que se valem de referido instrumento defensivo, com corte até junho de 2006, também será procedido, de modo a saber que peculiaridades podem ser observadas em nosso ambiente.

Ainda quanto ao objetivo do trabalho, serão apreciadas teorias que procuram explicar o comportamento de administradores de companhias com poison pills em termos de alinhamento de interesses pessoais com os da firma. Ora, o ganho de estabilidade advindo das poison pills não confere aos administradores um maior grau de discricionariedade e arrojo na eleição de projetos mais rentáveis e mais arriscados, que, por via de consequência, maximizam a riqueza dos acionistas? Ou, alternativamente, dita estabilidade não provoca a acomodação natural dos administradores, os quais não têm maior preocupação quanto à performance da firma, fazendo preponderar seus interesses pessoais?

Conforme definição de Downes e Goodman (1993), take over é a mudança no controle acionário de uma companhia. A alteração no controle pode ser amistosa ou uma oferta de compra hostil que a companhia-alvo (target company) pode combater com técnicas para afastar investidores agressivos (shark repellent). Normalmente, tenta-se uma aquisição hostil (com o objetivo de substituir a administração existente) por meio de ofertas públicas de aquisição de ações (OPA) (tender offer). Outras abordagens poderiam ser iniciativas de incorporação apresentadas aos membros do Conselho de Administração, acúmulo de ações em circulação no mercado ou a disputa por procurações de voto (proxy fight) que visam a garantir a eleição de novos membros no Conselho de Administração.

2 Testemunhou-se, recentemente, uma longa batalha envolvendo a aquisição hostil do Grupo Arcelor, com sede em Luxemburgo, pelo Grupo indiano Mittal Steel. Dentre as estratégias utilizadas pela Arcelor para persuadir seus acionistas a não aceitarem a OPA, foi proposta a distribuição de 1,20 euros por ação a título de dividendos, pelos resultados auferidos no exercício social de 2005, o que representou o dobro do ano anterior (VALOR ECONÔMICO, 17/02/2006, p. B5). 


\subsection{Relevância da Pesquisa}

O tema é novo no Brasil não tendo sido explorado academicamente. Recentemente, foram colocadas à prova as disposições antiaquisição no mercado brasileiro, em operação de oferta de aquisição hostil envolvendo de um lado Sadia e de outro Perdigão ${ }^{3}$. Em ter- mos de pesquisa acadêmica, compulsando os anais dos Congressos ENANPAD e USP de Controladoria e Contabilidade, com avaliação Capes Nacional "A", não foi localizado artigo que enveredasse por essa seara. Assim, um trabalho dessa natureza contribuirá para o desenvolvimento da literatura no Brasil.

\section{AQUISIÇÕES HOSTIS E POISON PILLS: ASPECTOS CONCEITUAIS E DISPOSIÇÕES LEGAIS/NORMATIVAS}

A condição sine qua non para que se tenha a perspectiva de ocorrência de uma operação de aquisição hostil de controle de uma dada companhia é a de que o seu capital ou, mais apropriadamente, o seu controle, esteja totalmente pulverizado no mercado. Em resumo, as companhias-alvo de uma aquisição hostil são eminentemente públicas ${ }^{4}$ na acepção da palavra, posto que não pertencem a nenhum indivíduo, entidade ou grupo que possa ser identificado.

A noção de capital pulverizado ${ }^{5}$ está arraigada na definição de ação em circulação, ou no termo correspondente em inglês, mais usualmente utilizado pelos agentes de mercado, free float (flutuação livre). Tal é encontrada no artigo $4^{\circ}$ - $\mathrm{A}, \$ 2^{\circ}$ da Lei $6.404 / 76$, com alteração promovida pela Lei 10.303/01. Assim, está consignado:

Consideram-se ações em circulação no mercado todas as ações do capital da companhia aberta menos as de propriedade do acionista controlador, de diretores, de conselheiros de administração e as em tesouraria.

Embora não esteja legalmente prevista na definição, entende-se que deveriam ter sido contempladas no rol de ações a serem expurgadas, para cômputo do montante em circulação, as ações de titularidade de pessoas vinculadas ao controlador e aos administradores, assim como aquelas de titularidade daqueles que exerçam quaisquer funções consultivas para a companhia ${ }^{6}$. Esse entendimento, tecnicamente, prende-se ao fato de ditos indivíduos estarem impedidos de negociar, livremente, suas ações quando da existência de ato ou fato relevante associado à companhia, que não seja de domínio público ${ }^{7}$.

A título de ilustração, seja considerado um exemplo bem simples para facilitar a fixação do conceito ora discutido. A companhia "Y" possui 1.000 ações emitidas, sendo 500 ações ordinárias, 250 ações preferenciais classe A e 250 ações preferenciais classe B. Os controladores da companhia "Y" possuem 300 ações ordinárias e 50 ações preferenciais de cada classe; os 5 membros do Conselho de Administração possuem uma ação ordinária cada um, assim como os 4 membros da Diretoria; 20 ações preferenciais de cada classe encontram-se em

3 São citados como exemplos de aquisição via mercado, embora não hostil, os controles de Brahma e a Lojas Americanas. Em 1982, segundo reportagem de O Estado de São Paulo (18/07/2005) intitulada "Lojas Renner são única com controle disperso", a Lojas Americanas teve seu controle adquirido na Bovespa pelos investidores Carlos Alberto Sicupira, Marcel Telles e Jorge Paulo Lehmann. Esses, ainda segundo a reportagem, adquiriram fatias expressivas do capital da Brahma em bolsa num primeiro momento para em seguida fecharem um acordo com outro acionista e adquirirem o controle da companhia.

40 termo "companhia pública" é uma tradução literal do correspondente em inglês publicly-held company, ou seja, companhia nas mãos do público, sob o controle do público. Assim, não tem nenhuma conotação de companhia estatal, pertencente a um ente público. É uma realidade do mercado acionário norte-americano, cujas grandes companhias abertas não possuem um controlador ou grupo controlador, ficando a cargo do administrador exercer o poder de controle. Desse fenômeno surgem teorias em Finanças, como a da Agência, que tenta explicar as relações e conflitos existentes entre acionistas e administradores.

50 termo mais adequado a utilizar no Brasil é "controle" pulverizado, posto que, em decorrência do ambiente legal societário brasileiro permitir a existência de mais de uma classe e espécie de ações, para as companhias abertas constituídas antes da Lei 10.303/01 é possivvel haver controle concentrado tão-só com 16,67\% do capital mais uma ação, não obstante poder haver a total pulverização de 83,33\% do capital no mercado.

6 Essa lacuna foi preenchida com definição mais ampla dada pela Instrução CVM n 361/02, art. $3^{\circ}$, iniciso III.

7 Assim adverte a Instrução CVM n. 358/02, em seu artigo 13. Nunca é demais lembrar que o crime de uso indevido de informação privilegiada - insider trading - foi tipificado com o advento da Lei 10.303/01, que promoveu a inserção do artigo 27-D na Lei 6.385/76. A pena para aqueles que cometerem desvios dessa natureza é de reclusão, variando de 1 a 5 anos, e multa de 3 vezes o montante da vantagem ilícita. 
tesouraria ${ }^{8}$; as ações remanescentes estão distribuídas no mercado. Com base nessas informações seria possível obter o free float de cada papel? A Tabela $1 \boldsymbol{O}$ detalha os cálculos.

Observe-se que a coluna ações "No Mercado" é o resultado do total de ações emitidas líquido de ações detidas pelo controlador, membros de Conselho de Administração e Diretoria, além das ações em tesouraria. Referida coluna evidencia as ações em circulação no mercado. Pelo free float de ações ordinárias de 38,20\% (191/500), chega-se à conclusão de que é impossível a companhia "Y" ser alvo de uma aquisição hostil de controle. Não há quantidade suficiente de ações no mercado que permitam tal intento. A troca de controle só será possível mediante sua alienação pelo atual controlador.

Nesse particular, convém dissipar eventuais dúvidas acerca do que vem a ser uma alienação de controle. $\mathrm{O}$ instituto da alienação do controle acionário, previsto no artigo 254-A da Lei 6.404/76, com alteração promovida pela Lei $10.303 / 01$, diferentemente do instituto da aquisição do controle, previsto no artigo 257 da Lei 6.404/76, é uma forma tradicional de alteração de controle das companhias abertas brasileiras, em virtude de nossa realidade empresarial ser a de ações, com poder de voto, concentradas.
Objetivamente, a alienação de controle acionário dá-se por meio de uma operação privada, em que vendedor e adquirente negociam livremente, sem a intervenção governamental, e chegam a um preço que, necessariamente, excede a cotação em bolsa das ações da companhia (obviamente se essas tiverem um mercado ativo para o seu papel). Tal fenômeno é explicado racionalmente do ponto de vista econômico, visto que, ao adquirir parcela dos ativos líquidos da companhia, cujo controle está sendo alienado e, por consequência, o direito a fruir os benefícios econômicos por eles gerados, o comprador acaba pagando, no bojo do preço acordado, um prêmio por levar consigo o direito de controlar 100\% desses ativos líquidos (se o poder de controle transferido no caso for pleno). Companhias que se enquadram no perfil do exemplo analisado (Cia. "Y") são envolvidas em operações de alienação, quando o poder de controle é transferido.

Um desdobramento societário importante de uma operação de alienação de controle diz respeito à oferta pública de aquisição de ações - OPA (tender offer), que deve ser formulada pelo proponente comprador aos demais acionistas detentores de ações com poder de voto ${ }^{9}$ da companhia cujo controle está sendo transferido. Alternativamente, o

Tabela 1 Distribuição acionária da Companhia " $Y$ "

\begin{tabular}{l|c|c|c|c|c|c|c} 
& Controlador & $\begin{array}{c}\text { Membros } \\
\text { CA }\end{array}$ & $\begin{array}{c}\text { Membros } \\
\text { Diretoria }\end{array}$ & $\begin{array}{c}\text { Em } \\
\text { Tesouraria }\end{array}$ & No Mercado & Total & Free Float \\
\hline Ações Ord. & 300 & 5 & 4 & - & 191 & 500 & $38,20 \%$ \\
\hline Ações Pref. A & 50 & - & - & 20 & 180 & 250 & $72,00 \%$ \\
\hline Ações Pref. B & 50 & - & - & 20 & 180 & 250 & $72,00 \%$ \\
\hline Total & 400 & 5 & 4 & 40 & 551 & 1.000 & $55,10 \%$ \\
\hline
\end{tabular}

8 É bom ressaltar que a disciplina de operações de aquisição de ações para a manutenção em tesouraria, dada pela Instrução CVM n. 10/80, em seu artigo $3^{\circ}$, com nova redação conferida pela Instrução CVM n. 268/97, restringe a compra de até 10\% das ações em circulação no mercado de cada classe, incluídas, nesse percentual, as ações mantidas em tesouraria por sociedades controladas e coligadas.

9 Embora a Lei 6.404/76, em seu artigo 254-A, estenda a OPA de alienação de controle a todos os acionistas titulares de ações com direito de voto, a CVM, na regulamentação do dispositivo legal, por intermédio da Instrução CVM n. 361/02, em seu artigo 29, restringiu a OPA às ações às quais seja atribuído o pleno e permanente direito de voto por disposição legal ou estatutária. Logo, aqueles acionistas titulares de ações preferenciais, que estejam sem receber dividendos fixos ou mínimos a que façam jus por 3 exercícios sociais consecutivos, ou por período inferior se previsto estatutariamente, que adquiram, nos termos do artigo 111 , $\S 1^{\circ}$ da Lei 6.404/76, o direito de voto, não são alcançados por OPA de alienação de controle. 
adquirente pode oferecer a esses acionistas a opção de permanecerem na companhia, mediante o pagamento de um prêmio derivado da diferença entre o valor de mercado das ações e o preço pago por cada ação do bloco de controle. A OPA, nesse caso, é obrigatória, devendo ser registrada na CVM. É uma condição indispensável para que o ato praticado seja consumado do ponto de vista legal. ${ }^{10}$

Já numa operação de aquisição de controle a realidade é outra. Mas antes de tratá-la, é importante apreciar um exemplo de uma companhia com capital pulverizado. Retomando o caso da companhia "Y", seja admitido que ela possua tão-só 800 ações ordinárias emitidas e os 5 membros do seu Conselho de Administração possuam uma ação cada um e os 4 membros da Diretoria a mesma quantidade. Há, ainda, 60 ações em tesouraria. A Tabela 20 sintetiza os números.

Verifica-se que, com um free float de 91,38\% (731/800) de ações ordinárias, a companhia "Y", nessa situação, é um alvo potencial para uma aquisição hostil de controle. Qualquer indivíduo ou grupo de indivíduos pode intentar a aquisição de controle da companhia "Y".

Com esse exemplo, pode-se, mais facilmente, definir o que vem a ser o instituto da aquisição de controle. Objetivamente, a aquisição de controle acionário dá-se mediante uma operação pública, via mercado de capitais, com a intermediação de uma instituição financeira, em que o adquirente formula uma oferta irrevogável - OPA, indistintamente, aos titulares de ações com poder permanente de voto (os vendedores não podem ser identificados previamente), circunscrita a um número suficiente de ações para a obtenção do controle. No caso da companhia "Y", a OPA de aquisição poderia limitar-se a 366 ações (50\% de free float mais uma ação). A OPA, nesse caso, é voluntária, visto que decorre de um ato de declaração vontade do adquirente. Seu registro, na CVM, é dispensado, sendo obrigatório somente no caso de a OPA de aquisição envolver a permuta de valores mobiliários (o pagamento do lote de ações da companhia-alvo com ações de uma terceira companhia).

Prosseguindo com a análise do exemplo, no caso concreto da companhia "Y", dado o seu alto free float de ações ordinárias, seus administradores estariam entregues à própria sorte no caso de uma OPA de aquisição de controle. Seria isso mesmo? Ora, uma aquisição hostil não decorre de um embate? Que medidas poderiam ser adotadas pelos administradores da companhia "Y" para imunizá-la?

Na década de 80, nos EUA, conforme assevera Varian (1988), as operações de aquisição hostil contagiaram o mercado. Firmas especializadas, grandes bancos de investimento, "vulture funds" (fundos abutres) começaram a perceber que as partes de uma companhia individualmente valiam mais do que o seu todo. Começaram, então, a serem engendradas estratégias visando à autodefesa da administração da companhia-alvo, as quais receberam a alcunha generalizada de poison pills.

Tabela 2 Distribuição das ações - Companhia "Y"

\begin{tabular}{l|c|c|c|c|c|c} 
& Membros CA & Membros Diretoria & Em Tesouraria & No Mercado & Total & Free Float \\
\hline Ações Ord. & 5 & 4 & 60 & 731 & 800 & $91,38 \%$ \\
\hline
\end{tabular}

10 As OPAs de alienação de controle representavam grandes óbices para os governos - Federal e Estaduais - privatizarem suas estatais, posto que encareciam as operações. Uma saída encontrada pelo Governo Federal foi a supressão do artigo 254 da antiga Lei 6.404/76, por meio de Projeto de Lei encaminhado ao Congresso Nacional, convertido na Lei 9.457/97, fato considerado à época um grande retrocesso por renomados juristas em matéria societária. Com o advento da Lei 10.303/01, o dispositivo foi restabelecido, passando a constar como artigo 254-A. 


\section{REVISÃO DE LITERATURA}

Ao se enveredar no universo das poison pills e de temas relacionados, como o das aquisições hostis, tem-se contato com considerável número de trabalhos acadêmicos, das mais variadas abordagens de pesquisa.

Varian (1998), ao abrir simpósio sobre takeovers, no periódico Journal of Economics Perspectives, traz ao conhecimento daqueles que se interessam pelo assunto alguns dados. Das 100 maiores operações de aquisição de controle registradas até o ano de 1984, 65 ocorreram entre 1981 e 1983, ao passo que 11 foram observadas antes de 1979. Durante os anos de 1981 e 1984, 45 transações envolveram bilhões de dólares. Dito autor manifestase no sentido de que as tomadas de controle servem como um instrumento de incentivo para que os administradores tenham um desempenho alinhado aos interesses dos acionistas. Se, porventura, falham na tarefa de maximizar o valor da firma, as tomadas de controle permitem aos acionistas sua substituição.

Jarrel et al. (1988), em seu trabalho de consolidação de estudos empíricos acerca do mercado de negociação de controle desde 1980, revelam, com base em dados do OCE (Office of The Chief Economist) da SEC (Securities and Exchange Commission), que os acionistas de firmas alvo de aquisições de controle bem sucedidas receberam prêmios de US\$ 54 bilhões (sobrepreço praticado nas ofertas públicas - OPAs, em relação à cotação dos papéis observada no mercado antes da formalização da operação).

O trabalho de Jarrel et al. (1988) pode ser considerado um compêndio sobre trabalhos empíricos sobre o tema, até a data de sua publicação. As seguintes teorias são apresentadas, com suas respectivas evidências empíricas, ressaltando-se que elas ainda devem ser submetidas a exaustivos estudos empíricos para serem refutadas ou aceitas no ambiente brasileiro:
Teoria da miopia de curto prazo e ineficiência dos takeovers: segundo a qual os participantes de mercado "enxergam" tão só performances de curto prazo, estando propensos a subavaliarem firmas com projetos de longo prazo. Por essa realidade, firmas com projetos de longo prazo seriam potenciais candidatas a operações de takeover. Nenhuma evidência empírica suporta essa teoria, conforme ressaltam Jarrel et al. (1988). Ditos autores destacam os estudos conduzidos pelo OCE, no ano de 1985, e por Hall, em 1987, que apresenta evidências de que muitas das operações de takeover, praticadas entre 1977 e 1986, foram direcionadas a firmas com baixa atividade em pesquisa e desenvolvimento (R\&D activity), fato que refuta a teoria.

Teoria da subavaliação da firma-alvo: segundo a qual os proponentes adquirentes em um takeover, embora façam ofertas que excedam o valor de cotação dos papéis da firmaalvo, ainda assim pagam um preço abaixo do valor intrínseco da firma, pelo fato de o mercado subavaliá-la. Tal situação justifica a postura adotada por administradores ao se defenderem contra a aquisição (via poison pills, por exemplo) e garantirem seus postos, em último caso visando aos interesses dos acionistas. Jarrel et al. (1988) advertem que as evidências empíricas indicam que a manutenção dos administradores, no longo prazo, não trazem ganhos para os acionistas. Quando uma firma-alvo consegue malograr a tentativa de takeover hostil, o seu valor ex post ao evento reverte-se para aproximadamente o seu valor ex ante. Citam como suporte empírico, os estudos de Bradley et al. de 1983; Easterbrook e Jarrel, de 1984; Jarrel, de 1985 e Ruback, de 1986.

Teoria da motivação tributária: segundo a qual as operações de takeover são praticadas com o fim de se auferirem benefícios tributários. Jarrel et al. (1988) afirmam que a maioria de estudos recentes atribui à mo- 
tivação tributária um papel não significativo na explicação do fenômeno. Citam os trabalhos de Auerbach e Reishus, de 1987, que concluem que a utilização de prejuízos fiscais e outros créditos tributários não são um fator significante para execução das operações e de Lehn e Poulsen, de 1987, que concluem que os prêmios pagos nas aquisições alavancadas (leveraged buyouts) estão diretamente relacionados com o potencial de benefícios tributários delas advindos, sugerindo, nesse caso, uma motivação.

Teoria da perda proporcionada aos titulares de títulos de dívida: segundo a qual os prêmios pagos em takeovers pelos proponentes compradores não decorrem de qualquer variação incremental de riqueza, mas a rigor representam uma redistribuição de riqueza; os titulares de títulos de dívida da firma adquirente (raider) são penalizados com a perda de valor dos seus títulos se a firma adquirente porventura paga em dinheiro por uma firma-alvo mais arriscada. $\mathrm{O}$ valor combinado das duas firmas permanece inalterado, uma vez que o declínio no valor dos títulos de dívida é compensado com o ganho em outra classe de valores mobiliários (ações ordinárias da firma-alvo, por exemplo). Jarrel et al. (1988) afirmam que não há evidência empírica que suporte tal teoria. Citam os trabalhos de Denis e Macconnell, de 1986, que, ao examinarem uma amostra contendo 132 firmas, no período entre 1962 e 1980, concluiram que, na média, os titulares de ações ordinárias, ações preferenciais conversíveis e não conversíveis, e títulos de dívida conversíveis da firma alvo ganham com o takeover. Os titulares de títulos de dívida não conversíveis da firma-alvo e títulos de dívida conversíveis e não conversíveis e ações preferenciais não conversíveis da firma adquirente não ganham tampouco perdem com o takeover; de Lehn e Poulsen, de 1987, que, na análise de 108 aquisições alavancadas, concluem que não há suporte empírico para a teoria da redistribuição de riqueza.

Teoria da perda proporcionada aos empregados: segundo a qual os prêmios advindos das operações de takeover são financiados às expensas dos funcionários ou via redução do quadro ou de benefícios e salários. Jarrel et al. (1988) afirmam que essa teoria redistributiva ainda não foi testada amplamente. Citam, contudo, o trabalho de Brown e Medoff, de 1987, que apresenta evidências estatísticas, com base nos salários praticados em Michigan e na sua taxa de emprego, que refutam a teoria. Os salários e a contratação, em média, aumentam nas firmas envolvidas em operações de takeover.

Uma outra contribuição de extrema importância do trabalho de Jarrel et al. (1988) e que tem uma relação mais direta com este estudo diz respeito ao inventário que fizeram das medidas defensivas antiaquisição (antitakeover amendments), utilizadas por administradores de firmas-alvo. Dividem-nas em duas categorias: medidas que dependem da aprovação de acionistas e medidas que não dependem de tal.

Das medidas que dependem da aprovação de acionistas são enumeradas:

Quorum qualificado (supermajority amendments): disposição que requer que operações de takeover sejam aprovadas por, no mínimo, 2/3 e, em alguns casos, 9/10 dos acionistas $^{11}$.

Cláusula do preço justo (fair price amendments): disposição aplicada somente a ofertas de aquisição não uniformes (two-tier bid ${ }^{12}$ ), em que o preço justo é determinado como o maior preço pago pelo ofertante por quais-

11 No Brasil, as operações de fusão, cisão, incorporação, a participação em grup o de sociedades e a dissolução da sociedade devem ser aprovadas, no mínimo, por acionistas que representam metade das ações com direito de voto, se maior quorum não for exigido no estatuto social, nos termos do artigo 136 da Lei 6.404/76. É bem verdade que nos termos do $\S 2^{\circ}$ do mesmo artigo 136 a Comissão de Valores Mobiliários pode autorizar a redução do quorum previsto no caso de companhia aberta com a propriedade das ações dispersa no mercado e cujas três últimas assembléias tenham sido realizadas com a presença de acionistas representando menos da metade das ações com direito a voto.

12 Downes e Goodman (1993) definem uma two-tier bid como sendo uma oferta de aquisição de controle, segundo a qual o adquirente oferece um preço mais elevado para as ações necessárias à aquisição de controle, oferecendo às demais ações um preço inferior. 
quer das ações da firma-alvo adquiridas durante um período específico.

Recapitalização em duas classes (dual-class recapitalization): disposição que reestrutura a distribuição de capital da firma. O objetivo é dotar a administração da firma e acionistas de grupos familiares (family owners) com poder de voto desproporcionalmente maior do que os dos demais acionistas.

Alterações na sede de constituição da companhia (change in the state of incorporation): expediente que permite à firma-alvo alterar o estado sede de sua constituição com o fim de possibilitar à sua administração valerse da legislação corporativa de determinados Estados que porventura seja mais restritiva às operações de takeover. Estados norte-americanos como Ohio, Indiana e Nova Iorque tornam os takeovers mais difíceis do que em outros Estados.

Redução nos direitos de voto múltiplo (reduction in cumulative voting rights): o expediente de cumular votos e obter procurações de voto (proxy contests) permite que grupo de minoritários elejam diretores, mesmo que a maioria se oponha. Logo, a redução ou eliminação dessa disposição dota os administradores da firma-alvo de mais poder ${ }^{13}$.

Em se tratando das medidas que não dependem da aprovação de acionistas são relacionadas:

Litígio envolvendo a administração da firma-alvo (litigation by target management): expediente segundo o qual os administradores da firma-alvo procuram valer-se de disposições de leis e regulamentos antitruste, leis federais e estaduais que disciplinam ofertas públicas e o mercado de valores mobiliários em geral, para inviabilizar ou postergar a operação de takeover e com isso aumentar o poder de barganha negocial.

Recompra de bloco de ações da firma-alvo (greenmail): acordo firmado entre a admi- nistração da firma-alvo e a administração da adquirente hostil (raider) por meio do qual se cessa a operação de takeover mediante a recompra do bloco de ações da firma-alvo, de titularidade da adquirente hostil, acrescido de um prêmio.

Pílulas envenenadas (poison pills): surgidas no ano de 1982, conforme salientam Jarrel et al. (1988), constituem-se em uma família de direitos contratuais de acionistas, ativados quando da ocorrência de um evento específico, como, por exemplo, uma OPA de controle ou a acumulação de um percentual específico de ações da firma-alvo. As poison pills, em regra, conferem ao acionista o direito de adquirirem ações adicionais da firmaalvo ou vendê-las para a firma-alvo por preços extremamente atrativos.

Legislações estaduais antiaquisição (state antitakeover amendments): em meio a apreciações de inconstitucionalidade de algumas dessas legislações por parte da Suprema Corte nos EUA, no ano de 1982, remanescem alguns códigos julgados contitucionais que servem como obstáculo a operações de takeover. Para os Estados, essas salvaguardas corporativas são benéficas por assegurarem a manutenção de empregos, o que, para os governantes, se constitui em um dividendo político.

Outra contribuição para a literatura relacionada ao tema é o trabalho de Malatesta e Walking (1988), circunscrito a avaliar empiricamente os efeitos das poison pills sobre a riqueza do acionista, sobre a lucratividade da firma e sobre a estrutura de controle.

Como parâmetro para estudo, ditos autores valem-se da teoria do entrincheiramento da administração (managerial entrenchment hypothesis) e da teoria do interesse do acionista (stockholder interest hipothesis). Pela primeira, as disposições antiaquisição aumentam os custos de substituição de ad-

13 No Brasil, o instituto do voto múltiplo, previsto no artigo 141 da Lei 6.404/76, faculta aos acionistas que representem, no mínimo, 1/10 do capital social da companhia com direito a voto, independentemente de previsão estatutária, cumular voto no processo de eleição de membros do Conselho de Administração (CA). À cada ação detida são atribuídos tantos votos quanto o número de membros do CA. 
ministradores ineficientes, reduzindo por consequência a riqueza dos acionistas. Pela segunda, as disposições antiaquisição permitem aos acionistas obterem um prêmio maior na iminência de uma OPA de controle e firmarem de modo mais eficiente contratos com seus administradores. Os resultados empíricos do trabalho de Malatesta e Walking (1988) tendem a dar suporte à teoria do entrincheiramento da administração.

Uma outra contibuição também relevante do trabalho de Malatesta e Walking (1988) é o tratamento taxonômico que dispensam às poison pills, definindo-as de modo didático. Classificam-nas em 4 tipos: planos de ações preferenciais (preferred stock plans); planos de direitos destacados (flip-over plans); planos de segundo bloco de ações (back-end plans) e planos de voto (voting plans).

Os planos de ações preferenciais (preferred stock plans) foram, exclusivamente, empregados antes de 1984. Conferem aos titulares de ações preferenciais a mesma vantagem política detida por acionistas ordinaristas: uma ação, um voto. Garantem, também, aos seus titulares dividendos superiores aos pagos a ações ordinárias, aspecto que serve de incentivo econômico para evitar uma conversão (caso as ações preferenciais sejam conversíveis em ordinárias). A característica central dos planos de ações preferenciais, enquanto espécie de poison pill, é a de que, havendo a aquisição de um percentual substancial das ações com poder de voto da firma-alvo (bloco de ações representando $30 \%$ ou $40 \%$ do total, por exemplo) por uma parte interessada, os titulares de ações preferenciais têm o direito de requerer da firma-alvo o resgate de suas ações, pelo maior preço pago pelo adquirente pelas ações preferenciais ou ordinárias da firma-alvo, a menos que o adquirente opere uma combinação de negócios com a firmaalvo (uma fusão, por exemplo), em um intervalo de tempo (usualmente 90 ou 120 dias). Nessa hipótese, na ocorrência da combinação de negócios (fusão, consolidação, reorgani- zação ou transferência de parte de ativos), os titulares de ações preferenciais fazem jus a permutarem seus valores mobiliários pelos da firma adquirente, cujo preço, para fins de relação de substituição, corresponderá à razão entre o maior preço pago pelo adquirente pelas ações preferenciais ou ordinárias da firma alvo e o menor preço das ações ordinárias do adquirente ou na data da conversão ou na data da efetivação da OPA de controle. Duas são as consequências para o adquirente: diluição e pesadas perdas.

Os planos de direitos destacados (flip-over plans) tiveram início em julho de 1984, sendo considerados uma segunda variante das poison pills. Por esse instrumento de defesa, a firma-alvo declara o dividendo de uma ação ordinária na forma de direitos de aquisição de alguma classe de seus valores mobiliários, usualmente ações ordinárias. $\mathrm{O}$ preço de exercício é fixado bem acima do preço de mercado do valor mobiliário subjacente (os autores revelam que no caso da companhia Crown Zellerbach, o preço de exercício foi fixado em US\$100, muito embora o seu valor de mercado fosse de US\$30). Há um vesting period (carência) de 10 dias para seu exercício, logo após uma parte interessada obtenha ou formule uma OPA por um percentual substancial de ações da firma-alvo (20\% ou $30 \%)$. Se essa parte interessada em uma fase posterior efetivar uma combinação de negócios (uma fusão, por exemplo), o direito "se destacará do valor mobiliário" (flip-over) e o seu titular fará jus a adquirir ações da firma resultante da operação por um desconto substancial do preço de mercado (usualmente $50 \%$ ). Sintetizando, no caso de um preço de exercício a US\$100 e a cotação da ação da firma resultante a US $\$ 50$, o titular do flip-over converterá um direito por 4 ações, caso o desconto seja de $50 \%$. Os autores revelam que, no caso do Hospital Corporation of América, o flip-over especificava um desconto de $90 \%$. Duas são as consequências para o adquirente: diluição e pesadas perdas. 
Já os planos de segundo bloco de ações (back-end plans) constituem-se na segunda poison pill mais utilizada e no terceiro tipo desenvolvido. Foram, primeiramente, adotados em outubro de 1984 e seu último registro data de março de 1986. Possuem, além de caracteristicas adicionais específicas, as mesmas das flip-over. Objetivamente, o dispositivo visa a fixar um preço mínimo no segundo bloco de ações de uma OPA two-tier. Garantem aos seus detentores o direito de converterem suas ações ordinárias por outros valores mobiliários ou caixa, pelo preço mínimo fixado no segundo bloco de ações (back-end). O direito à relação de troca pode ser extinto se o adquirente hostil fizer uma oferta pelas ações com back-end plans por um preço não inferior ao mínimo fixado no segundo bloco de ações (back-end). Além das consequências anteriores já observadas, esse instrumento encarece sobremaneira uma aquisição hostil.

No tocante aos planos de voto (voting plans), esse é o quarto e último tipo de poison pill observada até o ano de 1986. O primeiro registro desse tipo de poison pill data de abril de 1985. Por esse instrumento, se uma parte interessada adquirir um percentual substancial das ações com direito a voto da firma-alvo, os titulares de ações preferenciais passam a desfrutar de vantagens políticas especiais (supervoting privileges). Os autores informam que, no caso da companhia ASARCO, a aplicação de um voting plan teria por implicação transformar 99\% de ações ordinárias em $16,5 \%$ do total de votos disponíveis. Consequência para o adquirente: torna inócua a tomada de controle, uma vez que perde poder político, imediatamente após sua ocorrência.

Prosseguindo com a revisão de literatura, Meulbroek et al. (1990), ao testarem a teoria da miopia de curto prazo e os efeitos de shark repellents, prestam, também, grande contribuição acadêmica. Exploram modelo desenvolvido por Stein em 1988, segundo o qual a realidade de ameaças de takeover encoraja os administradores de firmas-alvo, subavaliadas, a comportarem-se de modo míope. Dada a assimetria de informações entre administradores e participantes de mercado, aqueles detêm mais conhecimento acerca de projetos de longo prazo da firma do que esses últimos. Se uma OPA hostil ocorre antes da maturação desses projetos de longo prazo, os acionistas das firmas-alvo sofrem perda de riqueza. A saída para os administradores dessas firmas alvo é produzir resultados de curto prazo, mediante o abandono ou substituição dos projetos de longo prazo, aumentando, dessa forma, as avaliações da firma efetuadas pelos participantes de mercado. O custo desse processo é reduzir a maximização de riqueza da firma. Assim sendo, estando o "contrato de longo prazo" firmado entre os acionistas e os administradores comprometidos, a saída é se valer do dispositivo golden parachute (paraquedas dourado), uma espécie de shark repellent (repelente de tubarão), para assegurar que os administradores serão, adequadamente, compensados na eventualidade de uma aquisição hostil.

Em termos de evidências empíricas, Meulbroek et al. (1990), utilizando métricas em cima de despesas com pesquisa e desenvolvimento (R\&D expenses), refutam a hipótese levantada por Stein. Constatam um declínio na métrica $\mathrm{R} \& \mathrm{D} / \mathrm{vendas}$ das firmas, imediatamente após a adoção de disposições antiaquisição.

A título de consolidação de disposições antiaquisição, convém reproduzir a definição de algumas outras estratégias, como as de shark repellent, extraídas de Downes e Goodman (1993), no rol a seguir:

- Shark-repellent (repelente de tubarão): medidas tomadas pela administração da companhia-alvo ou cláusulas contratuais que na mesma linha das poison pills inviabilizam as aquisições hostis. Um exemplo é a inserção de dispositivos nos contratos de trabalho celebrados com os administradores da companhia (membros de CA e diretoria), que garantam a esses pesadas indenizações, 
no caso de rescisões de seus contratos após uma aquisição hostil (golden parachute ou paraquedas dourado), o que torna precário o poder de controle de um proponente comprador da companhia-alvo, uma vez consumada a transação. Há, ainda, uma medida que compreende uma operação de incorporação de uma terceira companhia pela companhia-alvo (incorporação defensiva), com o objetivo de acionar disposições de normas antitruste de Reguladores do direito econômico e da livre concorrência ${ }^{14}$, caso em seguida seja formulada a OPA de controle. Outros exemplos de shark repellents são disposições estatutárias que conferem mandatos alternados aos membros de conselho de administração - staggered board (e com isso restringe o poder de atuação do adquirente hostil, via nomeações de novos membros) ou requerem um quorum qualificado (2/3 ou 3/4 de votos, por exemplo), para deliberação em Assembléia Geral de Acionistas, quando a matéria for OPA de controle, o que requer uma adesão substancial de acionistas à oferta.

- Pac man (denominação extraída de tradicional video game): operação defensiva segundo a qual a companhia-alvo começa a adquirir ações de companhia que seja sua potencial compradora, visando a inverter a situação. Intenta a aquisição hostil da potencial compradora. No Brasil, esse tipo de operação teria como reforço disposições da lei voltadas às participações recíprocas, que as vedam acima de determinados limites (art. 244 da Lei 6.404/76).

- Scorched-earth policy (política da terra arrasada): medida adotada pela ad- ministração da companhia-alvo que compreende ou a venda da principal linha de negócios da companhia-alvo ou a venda dos seus principais ativos (crown jewels) ou o planejamento do vencimento antecipado de todas as suas dívidas. Esse tipo de estratégia, no Brasil, esbarraria em disposições da lei, voltadas ao controle dos atos praticados pelos administradores (deveres e responsabilidades, disciplinados pelos artigos 153 a 160 da Lei 6.404/76).

- White knight (cavaleiro do bem): medida adotada pela administração da companhia-alvo que consiste em procurar um investidor amigável que esteja interessado em defendê-la de uma aquisição hostil, e propenso a formular uma OPA de controle concorrente. O investidor formula uma outra OPA com a qual a administração da companhiaalvo trabalhará no convencimento dos seus acionistas.

Dando continuidade, releva destacar mais uma contribuição para a literatura. Danielson e Karpoff (2006), ao estudarem as teorias do entrincheiramento da administração e do interesse do acionista, apresentam mais evidências acerca do comportamento do fenômeno poison pill. Medindo a performance operacional anormal das firmas com e sem poison pills, por meio de métricas construídas em cima do EBIT (earnings before interest and tax) e aplicando regressões sobre variáveis outras, refutam a hipótese do entrincheiramento da administração.

Encerrando essa seção do trabalho, podese afirmar que há de fato um número expressivo de estratégias que podem ser colocadas em prática, a depender, exclusivamente, da criatividade e do talento daqueles que as planejam. Muitas são as evidências empíricas

14 No Brasil, concentrações de grupos econômicos que apresentem riscos para a livre concorrência são apreciadas em conjunto pela Secretaria de Acompanhamento Econômico (SEAE) <http://www.fazenda.gov.br/seae/>, vinculada ao Ministério da Fazenda, Secretaria de Direito Econômico (SDE) <http://www.mj.gov. $\mathrm{br} / \mathrm{sde} />$, vinculada ao Ministério da Justiça, e pelo Conselho Administrativo de Direito Econômico (CADE), Autarquia Federal vinculada ao Ministério da Justiça <http://www.cade.gov.br>. 
que corroboram ou refutam determinadas teorias, assim como revelam os efeitos, em termos de riqueza, performance e rentabilidade, por exemplo, advindos da adoção de disposições anti-aquisição.

É de se salientar que, no Brasil, embora seja inexistente o mercado de aquisições hostis, não tendo sido documentada outra operação além do take over hostil envolvendo
Sadia e Perdigão, já citadas, algumas companhias brasileiras já utilizam disposições antiaquisição em seus estatutos sociais. Ora, que companhias seriam essas? Os propósitos da utilização desses dispositivos seriam únicos: defesa de uma aquisição hostil? São questões como essas que justificam um levantamento das caraterísticas de ditas companhias.

\section{COMPANHIAS ABERTAS BRASILEIRAS COM POISON PILLS}

De acordo com levantamento efetuado na base de dados do sistema IPE, desenvolvido e administrado pela Bovespa e compartilhado com a Comissão de Valores Mobiliários, com corte em junho de 2006, foram identificadas 7 companhias abertas brasileiras com cláusulas estatutárias antiaquisição. São elas: Submarino, Lojas Renner, Embraer, Perdigão, DASA, Natura e Ideiasnet.

Saliente-se que nem todas estão livres de um Acionista Controlador, o que por si só já confere o caráter peculiar da poison pill no ambiente brasileiro. Como justificá-la (a poison pill) para a situação em que a companhia possui Acionista Controlador? Muito possivelmente decorra da intenção do controlador em manter um certo grau de dispersão acionária no mercado, salvaguardando com isso a liquidez do papel da companhia ou mesmo objetive elidir uma eventual aquisição hostil, dado o grau de dispersão acionária da companhia.

\subsection{Companhias sem acionista controlador e controle negociado no mercado}

A Submarino, pelas informações públicas de que se dispõe, é hoje uma companhia com o seu controle negociado no mercado de capitais brasileiro. Extraindo a sua distribuição de capital do formulário IAN arquivado no sistema IPE, chega-se aos dados da Tabela $3 \bullet$, com o último evento societário realizado em 25/04/2006.
Verifica-se que seu free float é expressivo, podendo considerá-lo como virtualmente de 100\% (há que se expurgar ações detidas por administradores), pois não há nenhum indivíduo ou grupo de indivíduos que controle, isoladamente ou em conjunto, a companhia. No IAN, consta a informação de 97,47\% de free float.

Em termos de perfil de investidor, a companhia possui 1.848 investidores Pessoas Físicas e Pessoas Jurídicas e 464 investidores institucionais. Vale registrar também que não há acordo de acionista celebrado que discipline a apreciação de matérias em Assembléia Geral de Acionistas tampouco regule a forma pela qual será exercido o direito de voto.

Em termos de disposições antiaquisição, a Submarino tem em seu estatuto, no artigo

Tabela 3 Distribuição acionária da Submarino em 25/04/2006

\begin{tabular}{l|c|c}
\multicolumn{1}{c|}{ Nome Acionista } & Ações Ord. & \% \\
\hline $\begin{array}{l}\text { Natexis Bank } \\
\text { Populaires }\end{array}$ & 2.298 .700 & 4,48 \\
\hline $\begin{array}{l}\text { Fidelity Manag. } \\
\text { Research Co. }\end{array}$ & 2.638 .600 & 5,14 \\
\hline $\begin{array}{l}\text { Janus Capital } \\
\text { Magment LLC }\end{array}$ & 3.394 .740 & 6,61 \\
\hline $\begin{array}{l}\text { Capital Group } \\
\text { Internat. Inc }\end{array}$ & 1.872 .300 & 3,65 \\
\hline Outros & 41.159 .291 & 80,13 \\
\hline Total & 51.363 .631 & 100,00 \\
\hline
\end{tabular}


33, uma cláusula de poison pill, que obriga todo acionista que adquirir o total de $20 \%$ das ações de emissão da companhia, excluídas as ações em tesouraria, a fazer uma OPA para $100 \%$ das ações emitidas, no prazo máximo de 60 dias a contar da data da aquisição ou do evento que resultou na titularidade de ações na quantidade limite. É interessante notar que o parâmetro utilizado não é o das ações em circulação, mas, sim, o total de ações emitidas.

$\mathrm{O}$ artigo 33 , em seus parágrafos $1^{\circ}$ e $2^{\circ}$, prevê, ainda, o critério a ser utilizado para fixação do preço da OPA e a forma de sua liquidação. A operação deve ser liquidada em dinheiro, à vista, por preço ao menos igual ao valor de avaliação da companhia, apurado com base nos critérios, adotados de forma isolada ou combinada, de patrimônio líquido contábil, de patrimônio líquido avaliado a preço de mercado, de fluxo de caixa descontado, de comparação por múltiplos, de cotação das ações no mercado de valores mobiliários ou com base em outro critério aceito pela CVM, assegurada a revisão do valor da oferta, devendo o preço estar suportado por laudo de avaliação preparado por instituição de reputação internacional.

Outra companhia com o seu controle negociado no mercado de capitais brasileiro é a Lojas Renner. Sua distribuição de capital, conforme informação extraída de seu formulário IAN, arquivado no sistema IPE, com último evento societário datado de 21/03/2006, é a que segue na Tabela $4 \mathbf{0}$.

Tabela 4 Distribuição acionária das Lojas Renner em 21/03/2006

\begin{tabular}{l|r|r}
\multicolumn{1}{c|}{ Nome Acionista } & Ações Ord. & \multicolumn{1}{c}{$\%$} \\
\hline SmallCap WorldFound & 1.380 .000 & 5,68 \\
\hline Ações em Tesouraria & - & 0,00 \\
\hline Outros & 22.912 .363 & 94,32 \\
\hline Total & 24.292 .363 & 100,00 \\
\hline
\end{tabular}

Verifica-se que, tal qual a Submarino, a Lojas Renner, também, é detentora de expressivo free float, sendo virtualmente de 100\% (pois devem-se expurgar ações detidas por administradores), não havendo nenhum indivíduo ou grupo de indivíduos que controle isoladamente ou em conjunto a companhia.

No tocante ao perfil de seus investidores, esse compreende 868 Pessoas Físicas e Pessoas Jurídicas e 380 investidores institucionais. Não há Acordo de Acionistas que discipline a apreciação de determinadas matérias em Assembléia Geral tampouco oriente a forma pela qual será exercido o direito de voto.

Em se tratando de disposição antiaquisição, seu estatuto social, em seu artigo 44, traz uma poison pill. Requer que seja formulada OPA a todos os acionistas detentores das ações de emissão da companhia, sempre que algum acionista atingir o percentual de 20\% do total das ações emitidas, no prazo máximo de 60 dias a contar da data de aquisição ou do evento que resultou na titularidade de ações na quantidade limite.

$\mathrm{O}$ artigo 44 , em seus parágrafos $1^{\circ}$ e $2^{\circ}$, prevê, ainda, a forma de liquidação da operação e o parâmetro para a fixação do preço a ser utilizado na Oferta Pública de Aquisição (OPA). A operação deve ser liquidada em dinheiro, à vista, sendo o preço não inferior ao maior valor entre (i) o valor econômico apurado em laudo de avaliação; (ii) 120\% do preço de emissão das ações em qualquer aumento de capital realizado mediante distribuição pública, ocorrido no período de 24 meses que anteceder a data em que se tornar obrigatória a realização da OPA, devidamente atualizado pelo IPCA até o momento do pagamento e (iii) $120 \%$ da cotação unitária média das ações de emissão da Companhia durante o período de 90 dias anterior à realização da OPA na bolsa de valores em que houver o maior volume de negociações das ações de emissão da Companhia.

Dando continuidade, a Embraer é mais uma companhia aberta que, recentemen- 
te, passou a ter o seu controle negociado no mercado de capitais brasileiro. Compulsando o seu formulário IAN, arquivado no sistema IPE, na seção que trata da distribuição de capital, a Tabela $5 \nabla$ é apresentada, com último evento societário datado de 31/03/2006.

Embora a distribuição de capital denuncie que há acionistas com expressivas participações individuais no capital social da companhia, não há a figura do controle pleno tampouco do controle compartilhado, conforme informação disposta no campo 14, do item 2, da seção 3 do formulário IAN. Ademais, no campo 11, do item 1, da seção 3 do formulário IAN, a companhia revela ser o free float de seus papéis de $99,67 \%$.

Com relação ao perfil de seus investidores, esse compreende 21.189 Pessoas Físicas e Pessoas Jurídicas e 351 investidores institucionais. Não há Acordo de Acionistas que discipline a apreciação de determinadas matérias em Assembléia Geral tampouco oriente a forma pela qual será exercido o direito de voto.

Já quanto à disposição antiaquisição, o estatuto social da companhia, em seu artigo 55, apresenta uma poison pill diferenciada. Determina que sempre que algum acionista atingir o percentual de 35\% do total das ações emitidas pela companhia seja submetido, no prazo de 15 dias contados da data de aquisição ou do evento que resultou na titularidade

Tabela 5 Distribuição acionária da Embraer em 31/03/2006

\begin{tabular}{l|c|r}
\multicolumn{1}{c|}{ Nome Acionista } & Ações Ord. & \multicolumn{1}{c}{$\%$} \\
\hline Previ & 121.274 .000 & 16,42 \\
\hline Cia. Bozano & 72.889 .000 & 9,87 \\
\hline Sistel & 54.258 .000 & 7,35 \\
\hline BNDESPAR & 46.712 .000 & 6,32 \\
\hline J.P. Morgan & 290.592 .000 & 39,34 \\
\hline Outros & 152.886 .000 & 20,70 \\
\hline Total & 738.611 .000 & 100,00 \\
\hline \hline
\end{tabular}

de ações na quantidade limite, pedido para realização de OPA à União, titular de ação especial (golden share), o qual estará sujeito à decisão discricionária do ente público quanto à sua aceitação ou não. Caso a União acate o pedido, deverá ser formulada OPA a todos os acionistas detentores das ações de emissão da companhia, no prazo máximo de 60 dias a contar da data da aprovação do pedido. Caso a União não acate o pedido, o acionista deverá alienar todas as ações que excedam o limite estabelecido, no prazo de 30 dias contados da comunicação da negação.

$\mathrm{O}$ artigo 55, em seu parágrafo $4^{\circ}$, prevê que o preço a ser fixado na OPA resulte da fórmula: valor da ação mais prêmio. O valor da ação corresponderá ao maior valor entre: (i) cotação unitária mais alta atingida pelas ações de emissão da Companhia, durante o período de 12 meses anterior à realização da OPA, dentre os valores registrados em qualquer bolsa de valores na qual as referidas ações forem negociadas; (ii) o preço mais alto pago pelo Acionista Adquirente, durante o período de 36 meses anterior à realização da OPA, por uma ação ou lote de ações de emissão da Companhia; (iii) o valor equivalente a 14,5 vezes o EBITDA Consolidado Médio da Companhia (média aritmética dos EBITDAs Consolidados da Companhia relativos aos 2 exercícios sociais completos mais recentes) deduzido do endividamento consolidado líquido da Companhia, dividido pelo número total de ações de sua emissão e (iv) o valor equivalente a 0,6 vezes o valor dos pedidos firmes em carteira (Backlog) da Companhia, conforme a última informação por essa publicada, deduzido do endividamento consolidado líquido da Companhia, dividido pelo número total de ações de emissão da Companhia. O prêmio corresponderá a 50\% do valor da ação.

$\mathrm{O}$ artigo 55 , em seu parágrafo $8^{\circ}$, requer, também, que a operação seja liquidada em dinheiro, à vista, e a OPA seja instruída por laudo de avaliação preparado por instituição de reputação internacional. 
Uma outra companhia que se enquadra no grupo das anteriores, qual seja, sem controlador e com controle negociado no mercado, é a Idéiasnet. Sua distribuição de capital, conforme seu formulário IAN, arquivado no sistema IPE, com último evento societário datado de 08.12.2005, é a que segue na Tabela 60 .

Observe-se que, virtualmente, as ações da companhia possuem $100 \%$ de free float, pois conforme já salientado devem-se expurgar do aludido cômputo as ações detidas por administradores. Já o perfil de seus acionistas engloba 918 investidores Pessoas Físicas e Pessoas Jurídicas e 85 investidores institucionais. Não há Acordo de Acionistas.

Relativamente à disposição antiaquisição, o estatuto social da companhia, em seu artigo 29, apresenta uma poison pill extremamente sui generis. Primeiro, caracteriza o que vem a ser aquisição de controle (dentro de um capítulo que trata de alienação de controle), ao requerer que seja formulada OPA para $100 \%$ das ações de emissão da companhia toda vez que algum acionista ou grupo de acionistas reunidos por acordo atingir o percentual de $40 \%$ do total das ações emitidas pela companhia, devendo a OPA ser registrada no prazo de 30 dias do evento. Depois caracteriza o que vem a ser aquisição de participação relevante, ao requerer que seja formulada OPA

Tabela 6 Distribuição acionária da Idéiasnet. em 08/12/2005

\begin{tabular}{l|c|c}
\multicolumn{1}{c|}{ Nome Acionista } & Ações Ord. & \% \\
\hline $\begin{array}{l}\text { Fundo de Invest. } \\
\text { Ações Pactual }\end{array}$ & 16.201 .000 & 21,57 \\
\hline $\begin{array}{l}\text { Lorentzen Business } \\
\text { Development Ltda. }\end{array}$ & 4.482 .000 & 5,97 \\
\hline 727 Participações Ltda. & 7.440 .000 & 9,91 \\
\hline Carlos Mario Almeira & 4.425 .000 & 5,89 \\
\hline $\begin{array}{l}\text { M94 Fundo Invest. } \\
\text { Multimercado }\end{array}$ & 3.987 .000 & 5,31 \\
\hline Outros & 38.537 .000 & 51,33 \\
\hline Total & 75.072 .000 & 51,33 \\
\hline
\end{tabular}

para aquisição de ações em quantidade proporcional à participação adquirida, toda a vez que algum acionista ou grupo de acionistas reunidos por acordo atingir o percentual de $25 \%$ do total das ações emitidas pela companhia, devendo a OPA ser registrada no prazo de 30 dias do evento.

O estatuto social da companhia não disciplina a forma pela qual deverá ser liquidada a OPA tampouco parametriza o critério a ser utilizado para fixação de preço, restringindose tão só a requerer a extensão na OPA das mesmas condições que balizarem as operações que culminarem com a extrapolação dos limites de $25 \%$ e $40 \%$.

\subsection{Companhias com acionista controlador e controle negociado no mercado}

A Perdigão é um exemplo de companhia aberta que possui acionistas controladores $\mathrm{e}$ vale-se de instrumento antiaquisição em seu estatuto social. Reproduzindo quadro acerca da distribuição de seu capital no mercado, conforme disposto no formulário IAN da companhia, arquivado no sistema IPE, com último evento societário datado de 12/04/2006, esse reflete o que segue na Tabela $7 \bullet$.

Pode-se constatar que a Perdigão possui o seu controle compartilhado por quatro Fundações de Previdência: Previ - BB, Petros, Sistel e Fapes. Como era de esperar nessa situação e conforme informado no formulário IAN, há Acordo de Acionistas que disciplina, entre outras coisas, a forma pela qual será exercido o poder de voto e serão apreciadas determinadas matérias em Assembléia Geral de Acionistas.

É de salientar, ainda, que, embora a companhia possua Acionista Controlador, o seu controle está sendo negociado no mercado, pois segundo informação constante de seu formulário IAN, campo 11, item 1 da seção 3, o free float dos papéis da companhia é de 52,50\%.

No que concerne ao perfil de seus investidores, há 10.629 Pessoas Físicas e Pessoas 
Tabela 7 Distribuição acionária da Perdigão em 12/04/2006

\begin{tabular}{l|c|c}
\multicolumn{1}{c|}{ Nome Acionista } & Ações Ord. & $\%$ \\
\hline Previ - BB $\left(^{*}\right)$ & 20.513 .235 & 15,31 \\
\hline Petros $\left(^{*}\right)$ & 15.575 .469 & 11,63 \\
\hline Sistel $\left(^{*}\right)$ & 8.588 .232 & 6,41 \\
\hline Fapes $\left(^{*}\right)$ & 6.122 .652 & 4,57 \\
\hline Weg S/A & 10.005 .102 & 7,47 \\
\hline Real Grandesa & 4.738 .407 & 3,54 \\
\hline Valia - CVRD & 5.545 .185 & 4,14 \\
\hline Previ - Banerj & 1.997 .595 & 1,49 \\
\hline Ações em Tesouraria & 430.485 & 0,32 \\
\hline Outros & 60.440 .790 & 45,12 \\
\hline Total & 133.957 .152 & 100,00 \\
\hline
\end{tabular}

$\left.{ }^{*}\right)$ controladores

Jurídicas e 452 investidores institucionais detentores dos papéis da companhia.

Quanto à disposição antiaquisição, o estatuto social da companhia contempla em seu artigo 37 uma poison pill. Requer que seja formulada OPA a todos os acionistas detentores das ações de emissão da companhia, sempre que algum acionista atingir o percentual de $20 \%$ do total das ações emitidas, no prazo máximo de 30 dias a contar da data de aquisição ou do evento que resultou na titularidade de ações na quantidade limite.

$\mathrm{O}$ artigo 37 , em seus parágrafos $1^{\circ}$ e $2^{\circ}$, determina, ainda, que a operação seja liquidada à vista, em dinheiro, e o preço fixado na OPA seja o maior valor entre: (i) o valor econômico apurado em laudo de avaliação; (ii) 135\% do preço de emissão das ações em qualquer aumento de capital realizado mediante distribuição pública ocorrido no período de 24 meses que anteceder a data em que se tornar obrigatória a realização da OPA, devidamente atualizado pelo IPCA até o momento do pagamento e (iii) $135 \%$ da cotação unitária média das ações de emissão da Companhia durante o período de 30 dias anteriores à re- alização da OPA na bolsa de valores em que houver o maior volume de negociações das ações de emissão da Companhia.

$\mathrm{O}$ artigo 37, em seu parágrafo $4^{\circ}$, determina, também, que os laudos de avaliação sejam elaborados por duas instituições financeiras de primeira linha, ilibada reputação e notório conhecimento do setor alimentício, uma escolhida pela companhia e outra pelo acionista adquirente.

Prosseguindo, a DASA é mais uma companhia que possui acionista controlador e disposição antiaquisição em seu estatuto social. Reproduzindo quadro extraído do formulário IAN, arquivado no sistema IPE, acerca de sua distribuição de capital, essa é, assim, refletida, com o último evento societário datado de 07/04/2006, conforme a Tabela 80.

Observa-se que a DASA possui controle pleno, sendo esse exercido, individualmente, pela DASA Participações S/A. Conforme informado no formulário IAN, há Acordo de Acionistas arquivado na sede da companhia.

Uma outra informação importante, consignada no formulário IAN, diz respeito ao free float dos papéis da companhia, que se encontra no patamar de 62,05\%. Assim como a Perdigão, a DASA, embora possua Acionista Controlador, tem, também, o seu controle negociado no mercado. Em se tratando do perfil de seus investidores, 1.575 acionistas Pessoas Físicas e Pessoas Jurídicas são detentores de seus papéis, assim como 290 investidores institucionais.

Tabela 8 Distribuição acionária da DASA em 07/04/2006

\begin{tabular}{l|r|c}
\multicolumn{1}{c|}{ Nome Acionista } & Ações Ord. & \% \\
\hline $\begin{array}{l}\text { DASA } \\
\text { Participações S/A }\left(^{*}\right)\end{array}$ & 21.371 & 37,23 \\
\hline Ações em Tesouraria & & 0,00 \\
\hline Outros & 36.032 & 62,77 \\
\hline Total & 57.403 & 100,00 \\
\hline
\end{tabular}

(*) controlador 
Relativamente à disposição antiaquisição, o estatuto social da companhia, em seu artigo 41, apresenta uma poison pill. Requer que seja formulada OPA a todos os acionistas detentores das ações de emissão da companhia, sempre que algum acionista atingir o percentual de $15 \%$ do total das ações emitidas, no prazo máximo de 30 dias a contar da data de aquisição ou do evento que resultou na titularidade de ações na quantidade limite.

$\mathrm{O}$ artigo 41 , em seus parágrafos $1^{\circ}$ e $2^{\circ}$, determina, ainda, que a operação seja liquidada à vista, em dinheiro, e o preço fixado na OPA seja o maior valor entre: (i) o valor econômico apurado em laudo de avaliação; (ii) $100 \%$ do preço de emissão das ações em qualquer aumento de capital realizado, mediante distribuição pública, ocorrido no período de 12 meses que anteceder a data em que se tornar obrigatória a realização da OPA, devidamente atualizado pelo IPCA até o momento do pagamento; (iii) $100 \%$ da cotação unitária média das ações de emissão da Sociedade, durante o período de 90 dias anterior à realização da OPA, ponderada pelo volume de negociação, na bolsa de valores em que houver o maior volume de negociações das ações de emissão da Sociedade e (iv) 100\% do maior valor pago pelo acionista adquirente por ações da Sociedade em qualquer tipo de negociação, no período de 12 meses que anteceder a data em que se tornar obrigatória a realização da OPA.

O laudo de avaliação que instruirá a OPA deverá, nos termos do parágrafo $9^{\circ}$ do artigo 41, ser elaborado por instituição ou empresa especializada, com experiência comprovada.

\subsection{Companhia com acionista controlador e sem controle negociado no mercado}

Um único caso de companhia aberta com poison pill, que possui acionista controlador e não tem o seu controle negociado no mercado de capitais brasileiro é a Natura. Consultando seu formulário IAN, arquivado no sistema IPE, para checar a sua distribuição de capital, essa se apresenta conforme a Tabela $9 \boldsymbol{\nabla}$, com o último evento societário datado de 25/05/2004.

Observa-se que é praticamente impossível adquirir em mercado o controle acionário da companhia, uma vez que seu free float é baixo. Checando dita informação no IAN, esse situa-se no patamar de $25,18 \%$. Verificase, também, que o controle da companhia é exercido de modo compartilhado.

No que diz respeito ao perfil dos acionistas, há 2.303 investidores Pessoas Físicas e Pessoas Jurídicas e 498 investidores institucionais. Há, ainda, Acordo de Acionistas celebrado, que orienta a forma pela qual será exercido o direito de voto e como serão deliberadas determinadas matérias em Assembléia Geral.

Em se tratando de disposição antiaquisição, o estatuto social da companhia, em seu artigo 33, apresenta uma poison pill. Determina que seja formulada OPA a todos os acionistas detentores das ações de emissão da companhia, sempre que algum acionista atingir o percentual de $15 \%$ do total das ações emitidas, no prazo máximo de 60 dias a contar da data de aquisição ou do evento que re-

Tabela 9 Distribuição acionária da Natura em 25/05/2004

\begin{tabular}{l|c|c}
\multicolumn{1}{c|}{ Nome Acionista } & Ações Ord. & $\%$ \\
\hline Lisis Participações S/A $\left(^{*}\right)$ & 120.880 & 28,30 \\
\hline Utopia Participações S/A $\left(^{*}\right)$ & 115.350 & 27,00 \\
\hline Passos Participações S/A $\left(^{*}\right)$ & 28.452 & 6,66 \\
\hline RM Futura & 20.056 & 4,69 \\
\hline Participações S/A $\left(^{*}\right)$ & 28.452 & 6,66 \\
\hline ANP Participações S/A $\left(^{*}\right)$ & 4.473 & 1,05 \\
\hline Ações Administradores em Tesouraria & 1.980 & 0,46 \\
\hline Outros & 107.550 & 25,18 \\
\hline Total & 427.193 & 25,64 \\
\hline
\end{tabular}

${ }^{*}$ ) controlador 
sultou na titularidade de ações na quantidade limite.

$\mathrm{O}$ artigo 33 , em seu parágrafo $2^{\circ}$, prevê que o preço a ser fixado na OPA resulte da fórmula: valor da ação mais prêmio. $\mathrm{O}$ valor da ação corresponderá ao maior valor entre: (i) cotação unitária mais alta atingida pelas ações de emissão da companhia, durante o período de 12 meses anterior à realização da OPA, em qualquer bolsa de valores na qual as ações da companhia forem transacionadas; (ii) o preço unitário mais alto pago pelo acionista adquirente, a qualquer tempo, para uma ação ou lote de ações de emissão da Companhia e (iii) o valor equivalente a 12 vezes o EBITDA Consolidado Médio da Companhia (média aritmética dos EBITDAs consolidados da companhia relativos aos 2 exercícios sociais completos mais recentes) deduzido do endividamento consolidado líquido da Companhia, dividido pelo número total de ações de emissão da Companhia. O prêmio corresponderá a $50 \%$ do valor da ação.

$\mathrm{O}$ artigo 33 , em seu parágrafo $1^{\circ}$, requer, também, que a operação seja liquidada em dinheiro e à vista.

\section{CONCLUSÕES}

Ao se fazer uma incursão por um tema tão intrigante como esse das disposições antiaquisição, generalizadamente cunhadas pelos profissionais de mercado brasileiros com a expressão poison pills, constata-se o quão atrasado ainda está o capitalismo no Brasil em face de economias mais pujantes como a norte-americana. A bem da verdade, não se sabe se esse tipo de arranjo societário, moldado para companhias com controle negociado em bolsa, vingará no Brasil, tendo em vista a nossa cultura fortemente arraigada no controle corporativo, a nossa realidade institucional não consolidada e, não menos importante, o nosso ambiente instável de regulação.

A revisão de literatura levada a termo proporcionou ter-se uma idéia da dimensão do assunto no ambiente norte-americano. Operações de takeover ocorrem nos EUA desde a década de 50; as disposições antiaquisição foram engendradas de um modo mais sofisticado e criativo na primeira metade da década de 80, período considerado por Varian (1988) como a fase da "merger-mania"; vastos são os registros de trabalhos acadêmicos empíricos em periódicos internacionais voltados a descrever o fenômeno e a estudá-lo empiricamente.

Por fim, encerrando este estudo exploratório, espera-se que uma nova área de pesquisa empírica possa ser desenvolvida no Brasil. Teorias aqui apresentadas podem e devem ser objeto de investigações futuras, de modo a se contribuir com a literatura sobre o tema no Brasil. É de todo prudente considerar nos trabalhos empíricos aspectos idiossincráticos do mercado de capitais brasileiro e a própria prematuridade dessas companhias, antes de qualquer conclusão friamente calcada nos números.

\section{Referências}

Arcelor define estratégia contra Mittal. Valor Econômico, p. B5, 17 jul. 2006.

COMISSÃO DE VALORES MOBILIÁRIOS. Instrução CVM n. 10 de 14 de fevereiro de 1980. Dispõe sobre a aquisição por companhias abertas de ações de sua própria emissão, para cancelamento ou permanência em tesouraria e respectiva alienação. DOU, Brasília, 21 fev. 1980 .
Instrução CVM n. 268 de 13 de novembro de 1997. Altera o limite previsto no art. $3^{\circ}$ da Instrução 10/80. DOU, Brasília, 17 nov. 1997.

Instrução CVM n. 358 de 3 de janeiro de 2002. Dispõe sobre a divulgação e uso de informações sobre ato ou fato relevante relativo às companhias abertas; disciplina a divulgação de informações na negociação de valores mobiliários e na aquisição de lote significativo 
de ações de emissã̃o de companhia aberta, estabelece vedações e condições para a negociação de ações de companhia aberta na pendência de fato relevante não divulgado ao mercado. DOU, Brasília, 28 jan. 2002. . Instrução CVM n. 361 de 5 de mar de 2002. Dispõe sobre o procedimento aplicável às ofertas públicas de aquisição de ações de companhia aberta, o registro das ofertas públicas de aquisição de ações para cancelamento de registro de companhia aberta, por aumento de participação de acionista controlador, por alienação de controle de companhia aberta, para aquisição de controle de companhia aberta quando envolver permuta por valores mobiliários, e de permuta por valores mobiliários. DOU, Brasília, 7 mar. 2002.

DANIELSON, M. G.; KARPOFF, J. M. Do pills poison operating performance? Journal of Corporate Finance, Elsevier, n. 12, p. 536-559, 2006.

DOWNES, J:; GOODMAN, J. E. Dicionário de termos financeiros e de investimento. São Paulo: Nobel, 1993. JARREL, G. A. et al. The market for corporate control: the empirical evidence since 1980. Journal of Economic Perspectives, American Economic Association, v. 2, n. 1, p. 49-68, 1988.

Lojas Renner são única com controle disperso. O Estado de São Paulo, 18 jul. 2005. s/p.

MALATESTA, P. H.; WALKING, R. A. Poison pills securities: stockholder wealth, profitability, and ownership structure. Journal of Financial Economics, Elsevier, n. 20, p. 347-376, 1988.

MEULBROEK, L. K. et al. Shark repellents and managerial myopia: na empirical test. Journal of Political Economy, n. 5, v. 98, p. 1108-1117, 1990.

PRESIDÊNCIA DA REPÚBLICA. Lei 10.303 de 31 de outubro de 2001. Altera e acrescenta dispositivos na Lei n. 6.404, de 15 de dezembro de 1976, que dispõe sobre as Sociedades por Ações, e na Lei n. 6.385, de 7 de dezembro de 197.6, que dispõe sobre o Mercado de Valores Mobiliários e cria a Comissão de Valores Mobiliários. DOU, Brasília, 1 nov. 2001.

. Lei n. 6.404 de 15 de dezembro de 1976. Dispõe sobre as Sociedades por Ações. DOU, Brasília, 17 dez. 1976.

Lei n. 6.385 de 7 de dezembro de 1976. Dispõe sobre o mercado de valores mobiliários e cria a Comissão de Valores Mobiliários. DOU, Brasília, 9 dez. 1976. . Lei n. 9.457 de 5 de maio de 1997. Altera dispositivos da Lei n. 6.404, de 15 de dezembro de 1976, que dispõe sobre as sociedades por ações e da Lei n. 6.385, de 7 de dezembro de 1976, que dispõe sobre o mercado de valores mobiliários e cria a Comissão de Valores Mobiliários. DOU, Brasília, 6 maio 1997.

VARIAN, H. R. Symposium on takeovers. Journal of Economic Perspectives, American Economic Association, n. 1, v. 2 , p. $3-5,1988$ 